\title{
Methodological factors affecting gas and methane production during in vitro rumen fermentation evaluated by meta-analysis approach
}

\author{
Laura Maccarana ${ }^{1}$, Mirko Cattani ${ }^{1 *}$, Franco Tagliapietra ${ }^{2}$, Stefano Schiavon ${ }^{2}$, Lucia Bailoni ${ }^{1}$ and Roberto Mantovani ${ }^{2}$
}

\begin{abstract}
Effects of some methodological factors on in vitro measures of gas production (GP, $\mathrm{mL} / \mathrm{g} \mathrm{DM}$ ), $\mathrm{CH}_{4}$ production ( $\mathrm{mL} / \mathrm{g} \mathrm{DM})$ and proportion (\% $\mathrm{CH}_{4}$ on total GP) were investigated by meta-analysis. These factors were considered: pressure in the GP equipment $(0=$ constant; $1=$ increasing), incubation time $(0=24 ; 1=\geq 48 \mathrm{~h})$, time of rumen fluid collection ( 0 = before feeding; $1=$ after feeding of donor animals), donor species of rumen fluid $(0=$ sheep; $1=$ bovine), presence of $\mathrm{N}$ in the buffer solution ( $0=$ presence; $1=$ absence), and ratio between amount of buffered rumen fluid and feed sample (BRF/FS; $0=\leq 130 \mathrm{~mL} / \mathrm{g} \mathrm{DM} ; 1=130-140 \mathrm{~mL} / \mathrm{g} \mathrm{DM} ; 2=\geq 140 \mathrm{~mL} / \mathrm{g} \mathrm{DM}$ ). The NDF content of feed sample incubated (NDF) was considered as a continuous variable. From an initial database of 105 papers, 58 were discarded because one of the above-mentioned factors was not stated. After discarding 17 papers, the final dataset comprised 30 papers (339 observations). A preliminary mixed model analysis was carried out on experimental data considering the study as random factor. Variables adjusted for study effect were analyzed using a backward stepwise analysis including the above-mentioned variables. The analysis showed that the extension of incubation time and reduction of NDF increased GP and $\mathrm{CH}_{4}$ values. Values of $\mathrm{GP}$ and $\mathrm{CH}_{4}$ also increased when rumen fluid was collected after feeding compared to before feeding (+26.4 and $+9.0 \mathrm{~mL} / \mathrm{g} \mathrm{DM}$, for GP and $\mathrm{CH}_{4}$ ), from bovine compared to sheep ( +32.8 and $+5.2 \mathrm{~mL} / \mathrm{g} \mathrm{DM}$, for GP and $\left.\mathrm{CH}_{4}\right)$, and when the buffer solution did not contain N $\left(+24.7\right.$ and $+6.7 \mathrm{~mL} / \mathrm{g}$ DM for GP and $\left.\mathrm{CH}_{4}\right)$. The increase of BRF/FS ratio enhanced GP and $\mathrm{CH}_{4}$ production $(+7.7$ and $+3.3 \mathrm{~mL} / \mathrm{g}$ DM per each class of increase, respectively). In vitro techniques for measuring GP and $\mathrm{CH}_{4}$ production are mostly used as screening methods, thus a full standardization of such techniques is not feasible. However, a greater harmonization of analytical procedures (i.e., a reduction in the number of available protocols) would be useful to facilitate comparison between results of different experiments.
\end{abstract}

Keywords: Experimental factors, Gas production, In vitro rumen fermentation, Meta-analysis, Methane production

\section{Introduction}

In recent years in vitro gas production (GP) technique has been applied routinely to evaluate the nutritional value of ruminant feeds. The most diffused techniques were designed to measure GP from feed samples incubated in glass syringes at atmospheric pressure [1] or in fermentation vessels where gas is measured over the whole incubation time [2] or regularly vented at fixed times [3] or at

\footnotetext{
* Correspondence: mirko.cattani@unipd.it

1 Department of Comparative Biomedicine and Food Science (BCA),

University of Padova, Viale dell'Università 16, 35020 Legnaro (PD), Italy

Full list of author information is available at the end of the article
}

fixed pressure $[4,5]$. More recently, such equipment has been adapted to determine the composition of gases, particularly methane $\left(\mathrm{CH}_{4}\right)$ produced from in vitro rumen fermentation [6-8]. The current literature $[9,10]$ encompasses reviews which explored the effect of various factors influencing in vitro GP values, as procedures used to collect and to treat rumen fluid [11], the composition of the buffer [12], the type of GP equipment [13-15] and the ratios between fermentation fluid and feed sample size [8]. On the contrary, to our knowledge, no literature reviews have been produced to investigate factors affecting $\mathrm{CH}_{4}$ measures obtained in vitro. 
The objective of the present study was to evaluate factors affecting in vitro GP and $\mathrm{CH}_{4}$ production by means of the meta-analysis approach.

\section{Materials and methods Literature search}

An as wide as possible literature search was conducted using search generators of public data (i.e. Web of knowledge, Google scholar, Science direct, and Scopus) and contacts with researchers working in this field, to find scientific papers reporting data of gas and $\mathrm{CH}_{4}$ production obtained from in vitro fermentation of feeds or diets commonly used for ruminants. The web searches were conducted using the following keywords in different combinations: in vitro technique, rumen fermentation, gas production, methane production and ruminants.

\section{Factors selected}

The search strategy aimed at selecting articles focusing on the study of specific factors known to exert notable effects on in vitro gas and $\mathrm{CH}_{4}$ production. Specifically, the following factors were considered: the pressure in the GP equipment used, the incubation time, the collection time of rumen fluid, the donor species, the presence or absence of $\mathrm{N}$ in the buffer solution added to the rumen fluid, the NDF content of incubated feed samples, the amount of buffer solution (B), the amount of rumen fluid (RF), and the amount of feed sample incubated (FS). The correction of in vitro data for "blank" samples, despite its relevance, was not considered as most papers did not provide this information. The chemical composition of diet fed to animals used as donors of rumen fluid was not taken into account because of huge variability among studies. In any case, the review of [10] indicated that the diet of donor animals does not have a significant effect on in vitro GP, provided that it is able to enhance a sufficient microbial activity to sustain GP. This prerequisite is commonly ensured in all studies. Agitation (or not) of bottles during the incubation was not taken into account because this factor has been reported as having minor effects on in vitro GP [10]. Moreover, this information is absent in many of the considered manuscripts.

\section{Inclusion and exclusion of literature for the study and building of the starting dataset}

A total of 105 scientific papers were identified and initially screened for acceptability by checking if all publications reported the above-mentioned information. To be included in the database, papers had to report all values of GP, $\mathrm{CH}_{4}$, and $\mathrm{CH}_{4}$ proportion on total $\mathrm{GP}\left(\% \mathrm{CH}_{4}\right.$ on total GP), or at least two of them, so that the third variable could be calculated. Results of studies carried out by using continuous (i.e. dual flow) or semi-continuous (i.e. RUSITEC ) GP equipment were not considered in the study. Experiments conducted using alternative inocula (i.e. faeces) instead of rumen fluid were excluded from the database, as well as studies that did not declare the time of rumen fluid collection. After discarding 58 out of the 105 papers (Table 1), a starting dataset was built considering 47 articles published over the last $12 \mathrm{yr}$, accounting for a total of 393 observations (Table 2). Such observations included only control treatments, defined as feeds or diets incubated alone. Observations referred to effects of additives on in vitro GP and $\mathrm{CH}_{4}$ production were not considered, to avoid possible further confounding effects due to the presence of such compounds. In the dataset some unpublished data of completed studies were included [15].

\section{Data harmonization}

Because of the heterogeneity in GP and $\mathrm{CH}_{4}$ values reported among publications, data were adjusted to a uniform scale. All GP data were transformed to $\mathrm{mL}$ per gram of incubated DM. Likewise $\mathrm{CH}_{4}$ values were converted and expressed in terms of total $\mathrm{CH}_{4}$ production $(\mathrm{mL}$ per gram of incubated DM) and as a proportion of total GP (mL per $100 \mathrm{~mL}$ of total GP). When not otherwise specified, the weight of the sample was considered as fed (on a wet basis). To reconcile the weight of a feed sample into $g$ of incubated DM, values were corrected using the DM content of each sample. When DM was not indicated, a value of DM equal to $920 \mathrm{~g} / \mathrm{kg}$ was used, corresponding to the general DM mean content of feed samples included in the dataset. When papers presented GP and $\mathrm{CH}_{4}$ values in terms of moles, a correction was adopted using GayLussac's law, assuming that $1 \mathrm{~mol}$ was equivalent to $25.6 \mathrm{~L}$ of gas under atmospheric pressure and temperature conditions of GP equipment $\left(39^{\circ} \mathrm{C}\right)$. In the case of [16], $1 \mathrm{~mol}$ of gas was considered to be equivalent to $25.4 \mathrm{~L}$, as indicated by the authors. To convert values of GP and $\mathrm{CH}_{4}$ expressed as $\mathrm{mL}$ per gram of OM, the DM and ash contents of feed samples were considered. When $\mathrm{CH}_{4}$ values were expressed in $\mathrm{mg} / \mathrm{g}$, these values were converted into $\mathrm{mL}$ using Gay-Lussac's law and considering the molecular weight of $\mathrm{CH}_{4}$. When $\mathrm{CH}_{4}$ values were expressed as $\mathrm{mmol} / \mathrm{L}$, they were reconciled considering Gay-Lussac's law and GP values; when $\mathrm{CH}_{4}$ data were expressed as $\mathrm{mL} / \mathrm{L}$ they were reconciled considering only values of GP.

\section{Evaluation of the preliminary dataset (47 papers; 393 observations)}

Variables such as the pressure in the GP equipment used (constant vs. increasing; 162 vs. 231 observations, respectively), the incubation time ( $\leq 24$ vs. $\geq 48$ h; 297 vs. 96 observations, respectively), the collection time of rumen fluid (before or after feeding of donor animals; 224 vs. 169 observations, respectively), the donor species (sheep vs. bovine; 77 vs. 316 observations, respectively), 
Table 1 List of references excluded from the meta-analysis. Additional file 1

\begin{tabular}{ll}
\hline References & Reason for exclusion \\
\hline Salem, 2012 & Only gas production was measured \\
Abarghuei et al., 2014 & \\
Rodrigues et al., 2014 & \\
Salem et al., 2014 & \\
Elghandour et al., 2015 & \\
Lavrencic et al., 2015 &
\end{tabular}

Rojas Hernandez et al., 2015

Rossi et al., 2001

Wallace et al., 2006

Wood et al., 2009

Becker and van Wikselaar, 2011

Cao et al., 2012

Castro-Montoya et al., 2012

Poulsen et al., 2012

O'Brien et al., 2013

Rira et al., 2015

Aemiro et al., 2016

Lovett et al., 2004

Hu et al., 2005

At least one investigating factor was missing

Only methane $\left(\mathrm{CH}_{4}\right)$ production data were reported and not the total gas production (GP) or $\mathrm{CH}_{4}$ proportion on total GP (\% $\mathrm{CH}_{4}$ on total GP)
Tavendale et al., 2005

Lovett et al., 2006

Patra et al., 2006

Hassim et al., 2010

Kamalak et al., 2011

Sun et al., 2011

Baraka and Abdl-Rahman, 2012

Blanco et al., 2012

Banik et al., 2013

Kim et al., 2013

Lin et al., 2013

Naumann et al., 2013

Durmic et al., 2014

Nanon et al., 2014

Castagnino et al., 2015

Cobellis et al., 2015

Copani et al., 2015

Jayanegara et al., 2015

Liu et al., 2015

Pirondini et al., 2015

Qiao et al., 2015

Rajkumar et al., 2015

Saminathan et al., 2015

Theart et al., 2015
Table 1 List of references excluded from the meta-analysis. Additional file 1 (Continued)

Serment et al., 2016

Anele et al., 2011

Zhang et al., 2011

Meale et al., 2012

Pang et al., 2014

Polyorach et al., 2014

Gemeda and Hassen, 2015

Ungerfeld et al., 2007

Hart et al., 2008

Wang et al., 1998

Amelchanka et al., 2010

Soliva et al., 2011

Methane production data were indirectly predicted

Methane production data were indirectly predicted

Williams et al., 2011

Li et al., 2013

Wischer et al., 2013

and the presence of $\mathrm{N}$ in the buffer solution (presence vs. absence; 331 vs. 62 observations, respectively) were all coded as dichotomous variables, i.e., 0 or 1 in respective order. Syringes and vented bottles were considered as equipment working at constant pressure, whereas closed bottles were considered as apparatus operating at increasing pressure. Data of rumen fluid obtained at slaughterhouse were considered as collected before feeding and, thus, coded as 0 . The actual NDF content of feed sample $(426 \pm 168.5 \mathrm{~g} / \mathrm{kg})$, the amount of buffer $(35.3 \pm 11.79 \mathrm{~mL})$, the amount of rumen fluid $(13.9 \pm$ $5.34 \mathrm{~mL}$ ), and the amount of feed sample incubated $(0.41 \pm 0.170 \mathrm{~g} \mathrm{DM})$ were initially treated as possible continuous variables. The NDF content of feeds was the only chemical constituent considered because: i) it was the only analytical measure reported by all scientific papers taken into account; ii) the NDF fraction is commonly considered a good descriptor of fermentation properties of feeds and/or diets [17] and it is strictly related with gas and $\mathrm{CH}_{4}$ production [18].

Two preliminary analyses of data were carried out. The first aimed at investigating the best classification system for the incubation time variable. Two classes of incubation time ( 24 or $\geq 48 \mathrm{~h}$ ) were chosen as the final outcome of the first preliminary investigation. The second analysis was carried out to test the possibility of treating as continuous variables the amounts of buffer, rumen fluid, and feed sample used for in vitro tests. Because of their low variability within experiment, the three variables were not run separately in the statistical model, but they were included as the ratio between the buffered rumen fluid (mixture of buffer solution and rumen fluid) and the feed sample, here defined as the 
Table 2 List of preliminary references considered with their respective description of factors selected as possible sources of variation on total gas production (GP), methane $\left(\mathrm{CH}_{4}\right)$ production and proportion ( $\% \mathrm{CH}_{4}$ on total GP) ( $n=393$ observations, 47 papers). Additional file 2

\begin{tabular}{|c|c|c|c|c|c|c|c|c|c|c|}
\hline References & $\mathrm{N}^{\mathrm{a}}$ & Pressure $^{b}$ & $\begin{array}{l}\text { Incubation } \\
\text { time } e^{c} \text { h }\end{array}$ & Donor species $^{d}$ & Collection time & $N$ buffer $^{f}$ & $\begin{array}{l}\text { NDF, } \\
\mathrm{g} / \mathrm{kg}^{\mathrm{g}}\end{array}$ & $\mathrm{B}, \mathrm{mL}^{\mathrm{h}}$ & $\mathrm{RF}, \mathrm{mL}^{\mathrm{i}}$ & $F S, g D M$ \\
\hline Lila et al., 2003 & 6 & increasing & $6 ; 24$ & bovine & before feeding & yes & $0-473$ & 20 & 10 & 0.18 \\
\hline Lila et al., 2004 & 1 & increasing & 6 & bovine & before feeding & yes & 466 & 20 & 10 & 0.18 \\
\hline Getachew et al., 2005 & 28 & constant & $6 ; 24 ; 48 ; 72$ & bovine & after feeding & yes & $250-315$ & 20 & 10 & 0.18 \\
\hline Longo et al., 2006 & 8 & constant & 24 & sheep & before feeding & yes & $240-769$ & $50 ; 80$ & $20 ; 25$ & $0.46-0.92$ \\
\hline Bodas et al., 2008 & 11 & increasing & 24 & sheep & before feeding & yes & 450 & 40 & 10 & 0.55 \\
\hline Garcia-Gonzales et al., 2008a & 2 & increasing & 24 & sheep & before feeding & yes & 440 & 40 & 10 & 0.45 \\
\hline Garcia-Gonzales et al., 2008b & 1 & increasing & 24 & sheep & before feeding & yes & 386 & 40 & 10 & 0.52 \\
\hline Macheboeuf et al., 2008 & 8 & increasing & 16 & sheep & before feeding & no & 262 & 25 & 15 & 0.37 \\
\hline Soliva et al., 2008 & 26 & constant & 24 & bovine & before feeding & yes & $254-583$ & 10 & 20 & 0.28 \\
\hline Holtshausen et al., 2009 & 1 & increasing & 24 & bovine & after feeding & no & 347 & 15 & 5 & 0.50 \\
\hline Martínez et al., 2010 & 8 & constant & $8 ; 24$ & sheep & before feeding & yes & $374-499$ & 32 & 8 & 0.37 \\
\hline Sallam et al., 2010 & 3 & increasing & 24 & sheep & before feeding & no & $547-616$ & 50 & 25 & 0.46 \\
\hline Xu et al., 2010 & 15 & increasing & 24 & bovine & after feeding & yes & $126-749$ & 42 & 8 & 0.55 \\
\hline Araujo et al., 2011 & 1 & increasing & 16 & sheep & before feeding & yes & 203 & 50 & 25 & 0.46 \\
\hline Avila et al., 2011 & 1 & increasing & 48 & bovine & after feeding & no & 385 & 18 & 6 & 0.50 \\
\hline Guglielmelli et al., 2011 & 5 & increasing & 48 & bovine & slaughterhouse & no & $391-523$ & 74 & 5 & 0.93 \\
\hline Lee et al., 2011 & 2 & increasing & 24 & bovine & before feeding & yes & $116-451$ & 40 & 10 & $0.43-0.45$ \\
\hline Navarro-Villa et al., 2011a & 27 & increasing & 24 & bovine & before feeding & yes & $187-871$ & $33-43$ & $7-16$ & $0.28-0.64$ \\
\hline Navarro-Villa et al., 2011b & 4 & increasing & 24 & bovine & before feeding & no & $396-498$ & 40 & 10 & 0.46 \\
\hline Pellikaan et al., 2011 & 11 & increasing & 72 & bovine & after feeding & yes & $25-648$ & 40 & 20 & $0.45-0.48$ \\
\hline Purcell et al., 2011a & 9 & increasing & 24 & bovine & before feeding & no & $351-426$ & 40 & 10 & 0.46 \\
\hline Purcell et al., 2011b & 7 & increasing & 24 & bovine & before feeding & no & $458-643$ & 40 & 10 & 0.46 \\
\hline Theodoridou et al., 2011 & 4 & increasing & 24 & sheep & before feeding & no & $253-526$ & 26.6 & 13.3 & 0.55 \\
\hline Zhang and Yang, 2011 & 1 & constant & 48 & bovine & after feeding & yes & 524 & 50 & 25 & 0.46 \\
\hline Amaro et al., 2012 & 1 & increasing & 24 & bovine & slaughterhouse & yes & 383 & 33 & 17 & 0.39 \\
\hline Carrasco et al., 2012 & 1 & increasing & 17 & bovine & slaughterhouse & no & 179 & 32 & 8 & 0.40 \\
\hline Garcia-Gonzales et al., 2012 & 1 & increasing & 12 & sheep & after feeding & yes & 0 & 40 & 10 & 0.46 \\
\hline Hassanat et al., 2012 & 1 & increasing & 24 & bovine & after feeding & no & 331 & 17 & 3 & 0.18 \\
\hline Pirondini et al., 2012 & 2 & increasing & 24 & bovine & before feeding & yes & $321-492$ & 20 & 10 & 0.23 \\
\hline Ramin and Huhtanen, 2012 & 4 & constant & 48 & bovine & after feeding & no & 570 & 48 & 12 & $0.29-1.15$ \\
\hline Boguhn et al., 2013 & 8 & constant & 24 & sheep; bovine & before feeding & no & $375-398$ & 20 & 10 & 0.11 \\
\hline Geerkens et al., 2013 & 3 & constant & 24 & bovine & before feeding & no & $169-520$ & 20 & 10 & 0.11 \\
\hline Hansen et al., 2013 & 1 & constant & 48 & bovine & before feeding & yes & 465 & 60 & 30 & 0.46 \\
\hline Narvaez et al., 2013 & 3 & increasing & 48 & bovine & after feeding & no & 372 & 27 & 13 & 0.46 \\
\hline Patra and Yu, 2013a & 1 & increasing & 24 & bovine & after feeding & yes & 292 & 30 & 10 & 0.37 \\
\hline Patra and Yu., 2013b & 2 & increasing & 24 & bovine & after feeding & yes & $290-416$ & 30 & 10 & 0.37 \\
\hline Ramin et al., 2013 & 32 & constant & $24 ; 48$ & bovine & after feeding & yes & $249-613$ & 40 & 20 & 0.46 \\
\hline Tuyen et al., 2013 & 4 & increasing & 48 & bovine & after feeding & yes & $714-929$ & 40 & 20 & $0.42-0.52$ \\
\hline Bezabih et al., 2014 & 58 & increasing & $24 ; 72$ & bovine & after feeding & yes & $184-684$ & 40 & 20 & 0.46 \\
\hline Cattani et al., 2014 & 20 & $\begin{array}{l}\text { increasing } \\
\text { constant }\end{array}$ & 24 & bovine & before feeding & yes & $106-591$ & 40 & 20 & $0.36-0.38$ \\
\hline Elghandour et al., 2014 & 4 & increasing & 72 & bovine & before feeding & yes & 459-557 & 40 & 10 & 0.92 \\
\hline
\end{tabular}


Table 2 List of preliminary references considered with their respective description of factors selected as possible sources of variation on total gas production (GP), methane $\left(\mathrm{CH}_{4}\right)$ production and proportion ( $\% \mathrm{CH}_{4}$ on total GP) ( $n=393$ observations, 47 papers). Additional file 2 (Continued)

\begin{tabular}{|c|c|c|c|c|c|c|c|c|c|c|}
\hline Kim et al., 2014 & 2 & increasing & 24 & bovine & after feeding & yes & $137-519$ & 80 & 20 & 0.28 \\
\hline O'Brien et al., 2014 & 22 & increasing & 24 & bovine & before feeding & yes & $326-426$ & 40 & 10 & 0.46 \\
\hline Pal et al., 2014 & 8 & constant & 24 & sheep & before feeding & yes & $401-518$ & 20 & 10 & 0.18 \\
\hline Hatew et al., 2015 & 4 & constant & 24 & bovine & before feeding & yes & $378-441$ & 40 & 20 & 0.46 \\
\hline Pal et al., 2015 & 18 & constant & 24 & sheep & before feeding & yes & $266-523$ & 20 & 10 & 0.18 \\
\hline Ramin et al., 2015 & 3 & constant & 48 & bovine & after feeding & yes & $239-570$ & 40 & 20 & 0.93 \\
\hline
\end{tabular}

${ }^{a} N=$ number of observations per article

${ }^{\mathrm{b}}$ Pressure $=$ pressure produced in the GP equipment used

Incubation time $=$ duration of incubation

${ }^{\mathrm{d}}$ Donor species $=$ donor species of rumen fluid

eCollection time = origin of rumen fluid: if it was collected before (before feeding or at slaughterhouse) or after feeding of donor animals

${ }^{\mathrm{f}} \mathrm{N}$ buffer = presence of $\mathrm{N}$ in the buffer solution

${ }^{9} \mathrm{NDF}, \mathrm{g} / \mathrm{kg}=$ actual NDF content of feed samples used

${ }^{\mathrm{h}} \mathrm{B}, \mathrm{mL}=$ buffer incubated

' $R F, \mathrm{~mL}=$ rumen fluid incubated

${ }^{\mathrm{j}} \mathrm{FS}, \mathrm{g} \mathrm{DM}=$ feed sample incubated

$\mathrm{BRF} / \mathrm{FS}$ ratio. This choice was further motivated by the fact that this ratio has a relevant effect on in vitro GP and GP kinetics $[10,19]$. In the present study the BRF/FS ratio was coded into three classes (<130 vs. $130-140$ vs. > $140 \mathrm{~mL} / \mathrm{g} \mathrm{DM} ; 173,105$, and 115 observations, respectively) as 0 or 1 or 2 , in respective order.

\section{Data cleansing to obtain the final dataset}

The final dataset submitted to the statistical analysis accounted for only 339 (corresponding to 30 scientific papers) out of the 393 initial observations. Firstly, 26 observations were excluded as they were obtained using an incubation time shorter than $24 \mathrm{~h}$. After that, according to the indications suggested by [20] for meta-analysis, other 28 observations were discarded as: i) the continuous variable considered (NDF) was constant in the study (20 observations); and ii) studies accounted for a single observation (8 observations).

\section{Statistical analysis}

The latter dataset was analyzed using a mixed model analysis accounting for the random study effect, with the scope of eliminating possible confounding effects due to differences within and across studies, as suggested by [20].

To overcome a possible over-parameterization of the mixed model, a first analysis accounting for the random study effect via the PROC MIXED of SAS [21] was carried out, considering a variance component $(\mathrm{TYPE}=\mathrm{VC})$ covariance structure [20]. To take into account the different accuracies among studies as well, all dependent variables were weighed by the inverse of the squared standard error divided by the mean of all the squared standard errors, as suggested by [20]. At a later stage, data of GP and $\mathrm{CH}_{4}$, adjusted for the heterogeneity due to different studies, i.e., study effect [20], were analyzed using the backward elimination technique [22] of SAS (PROC REG; [21]). The exit level for each variable, i.e., the threshold of significance for excluding a variable from the model, was set at $P>0.10$. Multi-collinearity among predictor variables was analyzed through the variance inflation factor (VIF). According to [23], the multicollinearity can be considered not significantly inflated when the VIF is lower than 10. The collinearity among explanatory variables included in the multivariate stepwise analysis, was calculated in terms of minimum condition index, to exclude the presence of dependencies (i.e., common variance explained) among the considered variables. According to [24], there are no dependencies when the minimum condition index is lower than 30 .

\section{Description of the preliminary dataset (47 papers; 393 observations)}

The list of references excluded from the meta-analysis and the reasons for exclusion are given in Table 1 . The references entering the preliminary dataset and the corresponding description of factors are listed in Table 2. In most of the experiments (32 out of a total of 47), fermentations occurred in conditions of increasing pressure, and gas was accumulated into the GP system during the incubation; 14 studies were conducted at constant pressure, by a regular venting of fermentation gases, whereas one study applied both constant and increasing pressure. The majority of the in vitro experiments (27) were stopped at $24 \mathrm{~h}$; in 5 studies, fermentations lasted less than $24 \mathrm{~h}$, whereas 10 studies used an incubation time $\geq 48$ h. In 5 researches, different incubation times were compared. Rumen fluid used for in vitro tests was preferentially collected from bovine (34 studies), whereas 12 experiments used sheep as donors. One study compared rumen fluid collected from sheep or bovine. In most of the cases rumen fluid was 
collected before feeding of donor animals (before feeding in 27 studies; at slaughterhouse in 3 studies); however, in a relevant number of cases (i.e., 17 studies) rumen fluid was collected after feeding of donors. In a large number of experiments (32 out of a total of 47), rumen fluid was mixed with a buffer solution containing $\mathrm{N}$. The NDF content of feed samples incubated showed a high variability, ranging from a very low $(0 \mathrm{~g} / \mathrm{kg}$, for potato starch and corn starch) to an extremely high value (929 $\mathrm{g} / \mathrm{kg}$, for sugarcane bagasse). With the exception of two studies Additional file 1: (Longo et al., 2006; Navarro-Villa et al., 2011a), the amounts of buffer and rumen fluid used in the study presented no variability, whereas in 7 papers different amounts of feed sample were tested.

\section{Results}

Description of the final dataset (30 papers; 339 observations)

The mean and standard deviation (s.d.) values of in vitro GP, $\mathrm{CH}_{4}$ production and proportion, obtained considering the final dataset, are given in Table 3.

Table 4 shows the mean and s.d. values of in vitro GP $(\mathrm{mL} / \mathrm{g} \mathrm{DM}), \mathrm{CH}_{4}$ production $(\mathrm{mL} / \mathrm{g} \mathrm{DM})$ and $\mathrm{CH}_{4}$

Table 3 Means and standard deviation (s.d.) of total gas production (GP), methane $\left(\mathrm{CH}_{4}\right)$ production and proportion (\% $\mathrm{CH}_{4}$ on total GP) of the 339 observations belonging to 30 reference used for the final analysis. Additional file 2

\begin{tabular}{|c|c|c|c|c|c|c|c|}
\hline \multirow[t]{2}{*}{ References } & \multirow[t]{2}{*}{ No. ${ }^{a}$} & \multicolumn{2}{|c|}{$\mathrm{GP}, \mathrm{mL} / \mathrm{g} \mathrm{DM}$} & \multicolumn{2}{|c|}{$\mathrm{CH}_{4}, \mathrm{~mL} / \mathrm{g} \mathrm{DM}$} & \multicolumn{2}{|c|}{$\mathrm{CH}_{4}, \%$ on total GP } \\
\hline & & mean & s.d. & mean & s.d. & mean & s.d. \\
\hline Lila et al., 2003 & 3 & 200 & 31.0 & 76.0 & 23.26 & 37.6 & 6.05 \\
\hline Getachew et al., 2005 & 21 & 235 & 20.9 & 53.8 & 15.65 & 22.6 & 5.20 \\
\hline Longo et al., 2006 & 8 & 131 & 70.5 & 24.8 & 17.33 & 18.0 & 4.14 \\
\hline Soliva et al., 2008 & 26 & 129 & 49.5 & 15.0 & 10.46 & 10.6 & 3.72 \\
\hline Martínez et al., 2010 & 4 & 480 & 17.7 & 45.2 & 5.41 & 9.4 & 0.78 \\
\hline Sallam et al., 2010 & 3 & 72 & 33.8 & 7.3 & 3.61 & 10.1 & 0.61 \\
\hline Xu et al., 2010 & 15 & 163 & 75.5 & 16.9 & 3.90 & 12.1 & 4.51 \\
\hline Guglielmelli et al., 2011 & 5 & 141 & 16.6 & 24.5 & 5.23 & 17.3 & 2.32 \\
\hline Lee et al., 2011 & 2 & 194 & 65.8 & 23.8 & 8.27 & 12.3 & 0.07 \\
\hline Navarro-Villa et al., 2011a & 27 & 141 & 59.9 & 20.5 & 8.78 & 14.8 & 2.58 \\
\hline Navarro-Villa et al., 2011b & 4 & 158 & 14.5 & 35.3 & 1.80 & 22.4 & 0.95 \\
\hline Pellikaan et al., 2011 & 11 & 276 & 70.7 & 47.3 & 9.65 & 17.5 & 2.22 \\
\hline Purcell et al., 2011a & 9 & 183 & 7.7 & 25.1 & 1.04 & 13.7 & 0.36 \\
\hline Purcell et al., 2011b & 7 & 171 & 17.5 & 31.3 & 3.45 & 18.3 & 0.48 \\
\hline Theodoridou et al., 2011 & 4 & 133 & 5.3 & 33.0 & 6.60 & 24.5 & 4.49 \\
\hline Pirondini et al., 2012 & 2 & 243 & 40.3 & 40.3 & 5.73 & 16.6 & 0.35 \\
\hline Boguhn et al., 2013 & 8 & 292 & 17.9 & 44.2 & 5.53 & 15.1 & 1.42 \\
\hline Geerkens et al., 2013 & 3 & 307 & 52.4 & 50.7 & 9.29 & 16.5 & 0.41 \\
\hline Patra and Yu., 2013b & 2 & 191 & 12.5 & 77.5 & 4.60 & 40.6 & 5.09 \\
\hline Ramin et al., 2013 & 32 & 223 & 77.5 & 36.2 & 9.83 & 16.9 & 3.03 \\
\hline Tuyen et al., 2013 & 4 & 95 & 41.8 & 17.6 & 7.17 & 19.1 & 2.39 \\
\hline Bezabih et al., 2014 & 58 & 200 & 39.5 & 41.9 & 11.91 & 20.9 & 4.19 \\
\hline Cattani et al., 2014 & 20 & 192 & 77.6 & 23.0 & 8.03 & 12.3 & 1.28 \\
\hline Elghandour et al., 2014 & 4 & 224 & 51.8 & 17.0 & 7.62 & 7.4 & 2.91 \\
\hline Kim et al., 2014 & 2 & 337 & 120.4 & 22.0 & 9.22 & 6.4 & 0.43 \\
\hline O'Brien et al., 2014 & 22 & 201 & 2.8 & 34.1 & 4.56 & 17.0 & 2.19 \\
\hline Pal et al., 2014 & 8 & 147 & 22.5 & 35.1 & 6.55 & 24.5 & 6.37 \\
\hline Hatew et al., 2015 & 4 & 312 & 23.8 & 54.5 & 5.78 & 17.5 & 0.63 \\
\hline Pal et al., 2015 & 18 & 101 & 33.3 & 11.5 & 2.57 & 12.2 & 3.11 \\
\hline Ramin et al., 2015 & 3 & 275 & 43.7 & 36.5 & 5.97 & 13.3 & 0.46 \\
\hline
\end{tabular}

${ }^{\mathrm{a}}$ No. $=$ number of observations per article 
Table 4 Descriptive statistics of total gas production (GP), methane $\left(\mathrm{CH}_{4}\right)$ production and proportion $\left(\% \mathrm{CH}_{4}\right.$ on total GP) for the main sources of variation analyzed in the multivariate stepwise analysis after correction for the study effect ( $n=339$ observations, 30 papers)

\begin{tabular}{|c|c|c|c|c|c|c|c|}
\hline \multirow[t]{2}{*}{ Main factors } & \multirow[t]{2}{*}{$\mathrm{No}^{\mathrm{a}}$} & \multicolumn{2}{|c|}{$\mathrm{GP}, \mathrm{mL} / \mathrm{g} \mathrm{DM}$} & \multicolumn{2}{|c|}{$\mathrm{CH}_{4}, \mathrm{~mL} / \mathrm{g} \mathrm{DM}$} & \multicolumn{2}{|c|}{$\mathrm{CH}_{4}, \%$ on total GP } \\
\hline & & mean & s.d.b & mean & s.d. & Mean & s.d. \\
\hline \multicolumn{8}{|l|}{ Pressure } \\
\hline Constant & 145 & 198 & 94.4 & 31.8 & 17.94 & 15.7 & 5.76 \\
\hline Increasing & 194 & 185 & 61.4 & 32.4 & 15.29 & 17.6 & 5.95 \\
\hline \multicolumn{8}{|l|}{ Incubation time, h } \\
\hline 24 & 253 & 178 & 77.9 & 27.6 & 14.20 & 15.6 & 5.59 \\
\hline$\geq 48$ & 86 & 227 & 63.1 & 45.3 & 15.63 & 20.2 & 5.60 \\
\hline \multicolumn{8}{|l|}{ Collection time } \\
\hline Before feeding & 191 & 174 & 81.5 & 26.3 & 14.58 & 15.1 & 5.47 \\
\hline After feeding & 148 & 212 & 65.9 & 39.7 & 15.68 & 19.0 & 5.79 \\
\hline \multicolumn{8}{|l|}{ Donor species } \\
\hline Sheep & 49 & 162 & 116.6 & 24.5 & 15.60 & 15.9 & 6.40 \\
\hline Bovine & 290 & 195 & 67.7 & 33.4 & 16.29 & 16.9 & 5.85 \\
\hline \multicolumn{8}{|l|}{$N$ in the buffer } \\
\hline Presence & 296 & 191 & 78.4 & 32.2 & 17.07 & 16.8 & 6.18 \\
\hline Absence & 43 & 190 & 71.0 & 31.5 & 11.52 & 16.7 & 3.82 \\
\hline \multicolumn{8}{|l|}{$\mathrm{BRF} / \mathrm{FS}^{\mathrm{C}}$} \\
\hline$<130 \mathrm{~mL} / \mathrm{g} \mathrm{DM}$ & 134 & 172 & 77.6 & 25.0 & 12.74 & 14.7 & 5.54 \\
\hline $130-140 \mathrm{~mL} / \mathrm{g} \mathrm{DM}$ & 105 & 217 & 65.4 & 40.8 & 12.00 & 19.2 & 4.08 \\
\hline$>140 \mathrm{~mL} / \mathrm{g} \mathrm{DM}$ & 100 & 187 & 81.5 & 32.5 & 20.17 & 17.0 & 7.02 \\
\hline
\end{tabular}

${ }^{a} \mathrm{No}=$ number of observations accounted in each class

${ }^{b}$ s.d. = standard deviation of means

${ }^{\mathrm{c}} \mathrm{BRF} / \mathrm{FS}=$ ratio between buffered rumen fluid and feed sample

proportion on total GP for the different possible sources of variation taken into account for the 30 literature papers considered in the meta-analysis. The use of GP systems working at constant pressure (with gas venting), incubation time $\geq 48 \mathrm{~h}$, rumen fluid collected from bovine after feeding, and a BRF/FS ratio included between 130 and $140 \mathrm{~mL} / \mathrm{g} \mathrm{DM}$, determined an increase of GP values. Measures of $\mathrm{CH}_{4}$ were higher with incubation time $\geq 48 \mathrm{~h}$, with rumen fluid collected after feeding of donor animals, and with a BRF/FS ratio $>140 \mathrm{~mL} / \mathrm{g}$ DM. When $\mathrm{CH}_{4}$ data were expressed as proportion on total GP, values resulted greater at increasing pressure $(+12.1 \%$ compared to constant pressure $)$ and at increasing incubation times $(+29.5 \%$ with time $\geq 48 \mathrm{~h}$ compared to $24 \mathrm{~h}$ ), when collection of rumen fluid was performed after feeding (+25.8\% compared to before feeding), and when BRF/FS was $>140 \mathrm{~mL} / \mathrm{g}$ DM $(+30.6 \%$ and $+12.9 \%$, compared to BRF/FS $<130$ and $130 \leq \mathrm{BRF} / \mathrm{FS} \leq 140 \mathrm{~mL} / \mathrm{g}$ DM, respectively).

Table 5 shows the predictive equations for in vitro GP (mL/g DM), $\mathrm{CH}_{4}$ production $(\mathrm{mL} / \mathrm{g} \mathrm{DM})$ and $\mathrm{CH}_{4}$ proportion (\% on total GP). The predictive equations were the following:

$$
\begin{aligned}
\mathrm{GP}(\mathrm{mL} / \mathrm{g} \mathrm{DM})= & 141.0+7.9 \times \mathrm{IT}+26.4 \\
\times & \mathrm{CT}+32.8 \times \mathrm{DS}+24.7 \\
\times & \mathrm{N}+7.7 \times \mathrm{BRF} / \mathrm{FS}-0.02 \\
\times & \mathrm{NDF} \\
\mathrm{CH}_{4}(\mathrm{~mL} / \mathrm{g} \mathrm{DM})= & 21.8+4.2 \times \mathrm{IT}+9.0 \\
& \times \mathrm{CT}+5.2 \times \mathrm{DS}+6.7 \\
& \times \mathrm{N}+3.3 \times \mathrm{BRF} / \mathrm{FS}-0.009 \\
& \times \mathrm{NDF} \\
\mathrm{CH}_{4}(\% \text { on total GP })= & 15.0+0.9 \times \mathrm{PR}+1.2 \\
& \times \mathrm{CT}+0.7 \times \mathrm{N}+0.3 \\
& \times \mathrm{BRF} / \mathrm{FS}
\end{aligned}
$$

where $\mathrm{PR}=$ pressure conditions in the GP system $(0=$ constant; $1=$ increasing); IT $=$ incubation time $(0=24 \mathrm{~h}$; $1=\geq 48 \mathrm{~h}) ; \mathrm{CT}=$ collection time of rumen fluid ( $0=$ before feeding; $1=$ after feeding of donors); $\mathrm{DS}=$ donor species of rumen fluid ( 0 = sheep; 1 = bovine); $\mathrm{N}=$ nitrogen in the buffer $(0=$ presence; $1=$ absence $) ; \mathrm{BRF} / \mathrm{FS}=$ buffered rumen fluid and feed sample ratio $(0=\leq 130 \mathrm{~mL} / \mathrm{g} \mathrm{DM} ; 1$ $=130-140 \mathrm{~mL} / \mathrm{g} \mathrm{DM} ; 2=\geq 140 \mathrm{~mL} / \mathrm{g} \mathrm{DM}) ;$ and $\mathrm{NDF}=$ NDF content of feed sample incubated (g/kg DM). 
Table 5 Outcome of the backward stepwise multivariate regression analysis on predicted values obtained by correcting for the study effect and adjusting raw data for different accuracies ${ }^{\mathrm{a}}$ of the total gas production (GP), methane $\left(\mathrm{CH}_{4}\right)$ production and proportion ( $\% \mathrm{CH}_{4}$ on total GP)

\begin{tabular}{|c|c|c|c|c|c|c|}
\hline \multirow[t]{2}{*}{ Items } & \multicolumn{2}{|l|}{$\mathrm{GP}, \mathrm{mL} / \mathrm{g} \mathrm{DM}$} & \multicolumn{2}{|l|}{$\mathrm{CH}_{4}, \mathrm{~mL} / \mathrm{g} \mathrm{DM}$} & \multicolumn{2}{|c|}{$\mathrm{CH}_{4}, \%$ on total GP } \\
\hline & estimate \pm SE & $P$ & estimate \pm SE & $P$ & estimate \pm SE & $P$ \\
\hline Intercept & $141.0 \pm 5.24$ & $<0.01$ & $21.8 \pm 2.22$ & $<0.01$ & $15.0 \pm 0.31$ & $<0.01$ \\
\hline Pressure $^{b}$ & - & - & - & - & $0.9 \pm 0.17$ & $<0.01$ \\
\hline Incubation time ${ }^{c}$ & $7.9 \pm 3.30$ & 0.018 & $4.2 \pm 1.40$ & $<0.01$ & - & - \\
\hline Collection time $^{d}$ & $26.4 \pm 3.21$ & $<0.01$ & $9.0 \pm 1.37$ & $<0.01$ & $1.2 \pm 0.19$ & $<0.01$ \\
\hline Donor species ${ }^{e}$ & $32.9 \pm 3.95$ & $<0.01$ & $5.3 \pm 1.68$ & $<0.01$ & - & - \\
\hline$N$ in the buffer ${ }^{f}$ & $24.7 \pm 3.86$ & $<0.01$ & $6.7 \pm 1.64$ & $<0.01$ & $0.7 \pm 0.23$ & $<0.01$ \\
\hline $\mathrm{BRF} / \mathrm{FS}^{\mathrm{g}}$ & $7.7 \pm 1.59$ & $<0.01$ & $3.3 \pm 0.67$ & $<0.01$ & $0.3 \pm 0.10$ & $<0.01$ \\
\hline$N D F, g / k g ~ D M^{h}$ & $-0.02 \pm 0.007$ & $<0.01$ & $-0.009 \pm 0.0031$ & $<0.01$ & - & - \\
\hline$R^{b}$ & 0.48 & & 0.34 & & 0.27 & \\
\hline Max VIF & 1.76 & & 1.76 & & 1.77 & \\
\hline Max condition index ${ }^{j}$ & 11.11 & & 11.11 & & 11.88 & \\
\hline
\end{tabular}

${ }^{a}$ Adjustment for different accuracies of measurements in different studies was carried out by weighing raw data by the inverse of the squared standard error divided by the mean of all the squared standard errors (St-Pierre, 2001 [20])

${ }^{\mathrm{b}}$ class $0=$ constant or class $1=$ increasing pressure

'class $0=24 \mathrm{~h}$; class $1=\geq 48 \mathrm{~h}$ of incubation

${ }^{d}$ class $0=$ before feeding of donor animals or at slaughterhouse; class $1=$ after feeding of donor animals

${ }^{\mathrm{e}}$ species used as donor of rumen fluid; class $0=$ sheep; class $1=$ bovine

${ }^{f}$ class $0=$ presence; class $1=$ absence of $\mathrm{N}$ in the buffer

${ }^{9} \mathrm{BRF} / \mathrm{FS}=$ (buffered rumen fluid and feed sample ratio) class $0=<130 \mathrm{~mL} / \mathrm{g} \mathrm{DM}$; class $1=130-140 \mathrm{~mL} / \mathrm{g} \mathrm{DM} ;$ class $2=>140 \mathrm{~mL} / \mathrm{g} \mathrm{DM}$ )

hactual NDF content of feed sample used: treated as continuous variable

' $\mathrm{VIF}=$ variance inflation index. When value is less than 10, the predictor variables show no significant multicollinearity

${ }^{j}$ collinearity index. When value is less than 30 , the variables tested are independent

The values of GP and $\mathrm{CH}_{4}$ were influenced by IT $(P=$ 0.018 and $P=0.003$, for $\mathrm{GP}$ and $\mathrm{CH}_{4}$, respectively), $\mathrm{CT}$ $(P<0.001$ for both, in the same order $)$, DS $(P<0.001$ and $P=0.003$, in the same order $), \mathrm{N}(P<0.001$ for both), BRF/FS $(P<0.001$ for both), and NDF $(P=0.005$ for both) (Table 5). Values of $\mathrm{CH}_{4}$ proportion were influenced by PR $(P<0.001)$, CT $(P<0.001), \mathrm{N}(P=0.005)$, and BRF/ FS $(P=0.002)$. Values of $R^{2}$ were $0.48,0.34$, and 0.27 for $\mathrm{GP}, \mathrm{CH}_{4}$ production and proportion, respectively.

For all analyzed factors, the maximum VIF was lower than 10 (Table 5). The collinearity among explanatory variables, expressed as a maximum condition index was lower than 30, ranging from 11.11 to 11.88 (Table 5).

Predicted values of in vitro GP and $\mathrm{CH}_{4}$ production showed a correlation of 0.90 ; the relationship obtained regressing in vitro predicted $\mathrm{CH}_{4}$ production against in vitro predicted GP produced a slope greater than 1 and a negative intercept (Fig. 1). The correlation between predicted values of in vitro GP and $\mathrm{CH}_{4}$ proportion was weaker (coefficient of determination, i.e., $R^{2}=0.45$ ) (Fig. 2).

\section{Discussion}

\section{General considerations}

Over the last 10 years, in vitro GP technique has been largely adopted to evaluate fermentation properties of single feeds and diets for ruminants, as it is a fast and cost-effective procedure [10]. Up to now, several protocols of analysis are available, involving the use of different GP equipment, several incubation times, methods of rumen fluid collection, and different analytical procedures. For these reasons, values of GP and $\mathrm{CH}_{4}$ obtained from different in vitro experiments cannot be easily compared. Results of the present meta-analysis confirm

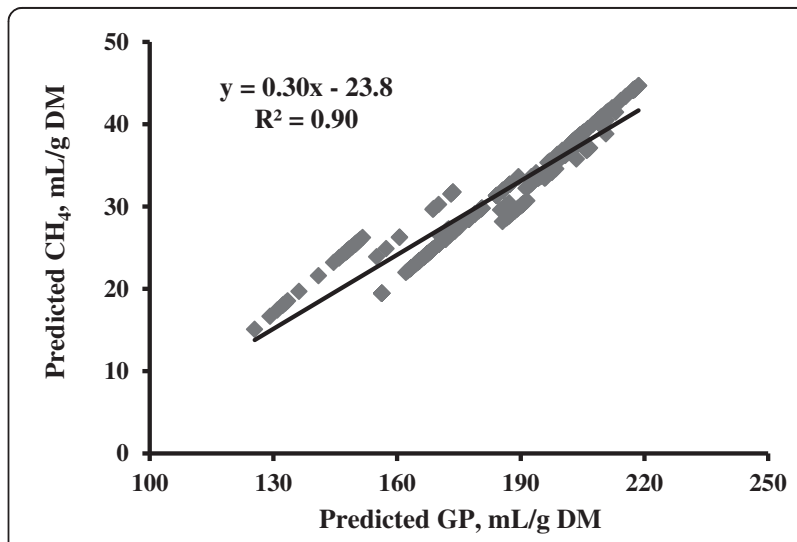

Fig. 1 Relationship between gas (GP) and methane $\left(\mathrm{CH}_{4}\right)$ productions using the predicted values obtained from the mixed model analysis aimed to removing the study effect (i.e., the heterogeneity of variance among studies) and considering also the correction of raw data for the different accuracies 


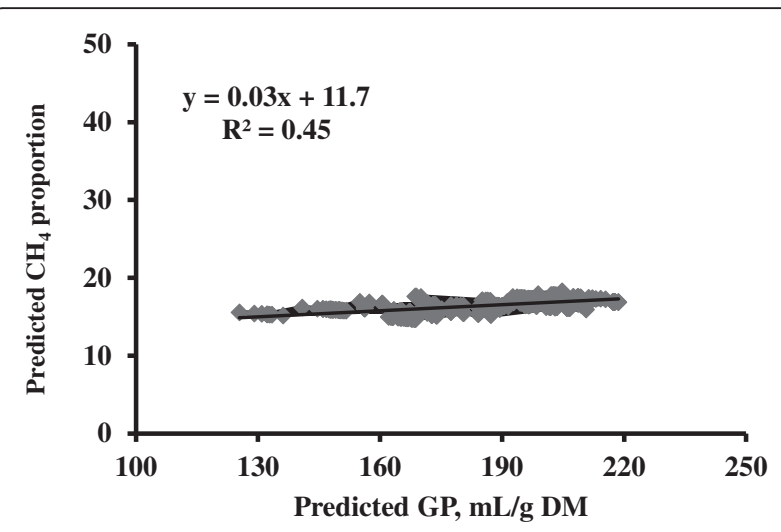

Fig. 2 Relationship between gas production (GP) and methane $\left(\mathrm{CH}_{4}\right)$ proportion (\% $\mathrm{CH}_{4}$ on total GP) using the predicted values obtained from the mixed model analysis aimed to removing the study effect (i.e., the heterogeneity of variance among studies) and considering also the correction of raw data for the different accuracies ${ }^{1}$

that some experimental factors, which are individually discussed in the following sub-chapters, can influence measures of GP and $\mathrm{CH}_{4}$ obtained in vitro. However, it also emerged that methodological factors considered in the present meta-analysis allowed to explain only in part the variability of GP and $\mathrm{CH}_{4}$ values. For example, the two predictive equations obtained for in vitro measures of $\mathrm{GP}$ and $\mathrm{CH}_{4}$ showed $\mathrm{a}^{2}$ of 0.48 and 0.34 , respectively. It is likely that the inclusion of a higher number of factors in the model would have contributed to improve the accuracy of statistical predictions. Unfortunately, this was not possible as information about methodological aspects and setting of the experiment (i.e., laboratory procedures, animal and/or feed characteristics) were often missing or not exhaustive. For instance, in the present meta-analysis, more than half of studies comprised in the initial dataset (58 out of a total of 105 papers) were discarded because they did not report any information about one, or more, of methodological factors which have well-known effects on in vitro GP [10]. It is quite evident that a detailed description of the experimental procedures would also facilitate the comparison among results obtained in different researches.

\section{Pressure conditions in GP equipment}

When in vitro equipment is used to measure GP and $\mathrm{CH}_{4}$, venting of gas is recommended to avoid overpressure conditions, which might disturb microbial activity [3] and cause a partial dissolution of $\mathrm{CO}_{2}$ in the fermentation fluid, thus underestimating GP measures [15]. From this meta-analysis it results that GP equipment operating at increasing pressure (i.e., without gas venting) provide, on average, lower measures of GP compared to those working at constant pressure. In contrast, values of $\mathrm{CH}_{4}$ proportion increased significantly when GP systems operating at increasing pressure were used. In this regard, [12] hypothesized that the increase of $\mathrm{CO}_{2}$ dissolved in the fermentation fluid, as result of overpressure conditions, would promote activity of methanogens. Additionally, when gas composition is analyzed, closed systems are often preferred, to avoid complexity of collecting vented gas into proper devices when open systems are used (i.e., gas-proof bags). With open systems, gas samples are collected from headspace of bottles at the end of incubation and analyzed for $\mathrm{CH}_{4}$ concentration $[6,7,25]$. These samples are considered to be most representative and to provide reliable measurements of $\mathrm{CH}_{4}$ because of the lower solubility in the fermentation fluid of $\mathrm{CH}_{4}$ compared to $\mathrm{CO}_{2}$ [6], hence measures are not affected by pressure changes in the bottles. According to this, the backward stepwise analysis did not highlight a significant effect of pressure on values of absolute $\mathrm{CH}_{4}$ production (mL/g DM). Differently, the $\mathrm{CH}_{4}$ proportion (\% $\mathrm{CH}_{4}$ on total $\mathrm{GP}$ ) was significantly influenced by pressure conditions in the GP system, resulting in greater values for equipment working at increasing pressure (closed systems). As recently observed [15], closed systems might underestimate in vitro GP, as a part of the $\mathrm{CO}_{2}$ is dissolved in the fermentation fluid, leading to a possible overestimation of the $\mathrm{CH}_{4}$ proportion on the total gas.

\section{Incubation time}

The positive correlation between incubation time and values of in vitro GP was expected and it is related to the progressive degradation of feed sample incubated over longer incubation times. Likewise, the significant increase of $\mathrm{CH}_{4}$ production, in absolute terms, with the progress of in vitro fermentations is consistent with literature. For instance, [26] found that $\mathrm{CH}_{4}$ production (mL/g DM) of seven commercial diets for dairy cows increased by $106.5 \%$ passing from 6 to $72 \mathrm{~h}$ of incubation. Similar results have been reported by [27] and by [28] Such tendency is explained by the fact that $\mathrm{CH}_{4}$ formation is primarily related to fermentation of fibrous fraction that has a slower degradation rate compared to other dietary components. Results observed from the present metaanalysis might have been partially conditioned by the large predominance of roughages in the dataset considered. Nevertheless, it must be underlined that in vitro $\mathrm{CH}_{4}$ production is often evaluated at a single incubation time, thus less information are provided about the kinetics of $\mathrm{CH}_{4}$ formation in vitro. In this regard, only 5 of the 30 experiments considered in this meta-analysis measured $\mathrm{CH}_{4}$ production at different incubation times.

\section{Rumen fluid: collection time and donor species}

Outcomes of this study showed that timing of rumen fluid collection had an impact on in vitro GP measures. More exactly, values of $\mathrm{GP}$ and $\mathrm{CH}_{4}$ production were greater 
when rumen fluid was collected after feeding the donor animals. This result might be explained by the presence of feed particles suspended in the rumen fluid, which can lead to an overestimation of the actual GP. This problem could be overcome through the incubation of blanks (bottles containing only the buffered rumen fluid), where the GP of rumen fluid can be determined and then used to adjust values of GP provided by experimental treatments [29]. However, [30] observed that microbial turnover begins more rapidly in blanks, thus they have a different GP rate compared to other treatments. On this basis, [31] discouraged the adjustment of GP data by using blank values.

This meta-analysis also shows that the time of rumen fluid collection is, to date, one of the least standardized procedures of the in vitro GP technique. This evidence is supported by the fact that some protocols of analysis used worldwide involve the collection of rumen fluid before feeding of donor animals [3, 32], whereas other authors suggest to feed animals before collection [2, 4]. In this regard, [1] indicated that rumen fluid used for in vitro tests should be collected before feeding of donor animals, as it has a less variable composition and, therefore, a more standardized effect on fermentations. However, the same authors [1] specified that the interval time occurring between the feeding of donors and the collection of rumen fluid should not exceed $16 \mathrm{~h}$, to ensure a sufficient microbial activity in the inoculum to sustain in vitro GP.

The largest part of in vitro experiments considered in the present meta-analysis had been carried out using rumen fluid collected from bovine. Results indicate that values of GP and $\mathrm{CH}_{4}$ were greater when incubations were conducted using rumen fluid of bovine. Effects of donor species on in vitro GP are still uncertain, and a univocal ranking of various rumen fluids based on GP is not possible [10]. In recent years, several studies have been conducted to compare bovine and sheep rumen fluid, but results were contrasting [33-35]. However, GP values obtained using rumen fluid from different species might be reconciled by the appropriate use of blanks [1], although not all authors are in agreement with the possible correction for blanks [30, 31], as mentioned above. As a confirmation, in a ring test where rumen fluids collected from bovine or sheep were used [11], correction of GP data for the relative blank samples gave a notable reduction of variability between laboratories.

\section{Nitrogen in the buffer solution}

The $\mathrm{N}$ in the buffer solution was found to be influential on in vitro GP and gas composition. More precisely, Nfree buffers increased $\mathrm{GP}, \mathrm{CH}_{4}$ production and proportion. To our knowledge, there is no evidence from literature that the buffer composition might influence $\mathrm{CH}_{4}$ measures obtained in vitro. The most experiments included in the dataset used a buffer solution containing N. In some cases, the composition of buffer used for in vitro tests is related to incubated feeds [10]. For instance, some buffers are rich in $\mathrm{N}$ and poor in energy sources, in order to evaluate energy contribution of feed samples to fermentations $[1,3]$. On the opposite, other buffers are $\mathrm{N}$-free, with the scope of evaluating the $\mathrm{N}$ contribution of high-protein feeds to in vitro fermentations [36]. It is likely that the buffer solution alone cannot modify in vitro GP and $\mathrm{CH}_{4}$ production in a significant way. More probably, some effects might appear when the mixture of buffer solution and feed sample is not balanced in terms of energy and $\mathrm{N}$, thus microbial activity and growth might be impaired, with actual consequences on the various parameters of in vitro fermentation [10].

\section{Ratio between buffered rumen fluid and feed sample}

Beuvink and Spoelstra [19] indicated that BRF/FS ratio must not exceed the proportion of $60 \mathrm{~mL}$ of buffered rumen fluid with $0.4 \mathrm{~g}$ OM of feed sample, which is $136 \mathrm{~mL} / \mathrm{g}$ DM. According to these authors, such ratio can avoid the exhaustion of buffer and the drop of $\mathrm{pH}$ under the threshold of 6.2, which causes a nonlinear relation between feed sample size and GP [32]. On a total of 30 papers (339 observations), only 17 papers (169 observations) reported $\mathrm{pH}$ values of fermentation fluids measured at the end of incubation. Within these latter observations, 35 values were lower than the threshold of 6.2 (on average $5.98 \pm 0.208$; ranging from a minimum of 5.45 to a maximum of 6.19). However, in these experiments the drop of $\mathrm{pH}$ was not perforce related to a low BRF/FS ratio. This suggests that other factors (i.e., kind of buffer, kind of substrate, ratio between buffer solution and rumen fluid) could affect the $\mathrm{pH}$ trend during in vitro fermentation. Therefore, the actual effect of the BRF/FS ratio on GP and $\mathrm{CH}_{4}$ values is difficult to comment on. Furthermore, considering the dataset of this meta-analysis, it is evident that $\mathrm{BRF} / \mathrm{FS}$ is one of the least standardized parameters for in vitro GP technique. Indeed, only 5 authors out of 30 followed the indications of [19], whereas 14 and 10 studies tested, respectively, lower $(<130 \mathrm{~mL} / \mathrm{g} \mathrm{DM})$ and higher ( $>140 \mathrm{~mL} / \mathrm{g} \mathrm{DM}$ ) BRF/FS ratios. One study tested both lower and higher ratios. Results of the present metaanalysis show that the BRF/FS ratio was positively related to in vitro values of $\mathrm{GP}, \mathrm{CH}_{4}$ production and proportion. In this regard, it could be hypothesized that, when the BRF/FS ratio increases, the fermentation fluid could be more capable of buffering the VFA produced from feed degradation, promoting the release of $\mathrm{CO}_{2}$ as indirect gas [9]. This process, in turn, would be expected to increase in vitro values of GP. Further, buffering action and maintenance of rumen $\mathrm{pH}$ would sustain the activity of methanogens, which are sensitive to acidification conditions [37], and thus the $\mathrm{CH}_{4}$ production might be increased. 


\section{NDF content of feed samples}

In line with our expectations, the NDF content of feeds incubated was one of the factors that affect in vitro measures of GP. More in detail, GP and NDF values were negatively correlated, as a high content of NDF in the feed is usually related to a reduced DM degradability [38] and, thus, to a low GP. For the same reason, the fibrous content of feeds was also negatively correlated with the absolute amount of $\mathrm{CH}_{4}$ produced in vitro $(\mathrm{mL} / \mathrm{g} \mathrm{DM})$. It must be underlined that most of the data considered in the final database of the meta-analysis (273 out of the 339 observations) were represented by feed samples with a high NDF content (>300 g/kg DM). Such data distribution is likely to have increased the incidence of the effect attributable to the NDF content. In this regard, the lower absolute $\mathrm{CH}_{4}$ production $(\mathrm{mL} / \mathrm{g} \mathrm{DM})$ of forages compared to concentrates, mainly due to the smaller extent of fermentation, was confirmed by several in vitro studies $[6,7,15,39]$.

\section{Conclusions}

Results of this meta-analysis show that some methodological factors can notably influence in vitro measures of GP and $\mathrm{CH}_{4}$ production. It is evident that a full standardization of in vitro GP techniques is not feasible, as some of these factors (i.e., GP equipment, donor species of rumen fluid) are necessarily related to laboratory routine and facilities, and to the specific aim of the experiment. In any case, a greater harmonization of analytical procedures (i.e., a reduction in the number of available protocols) would be useful to facilitate comparison between results of different experiments. Further, exhaustive information about analytical procedures would be always included in the scientific papers. For instance, in the present meta-analysis, more than half of studies were excluded from the final dataset because they did not report some information about laboratory procedures and/or animal and feed characteristics that can influence fermentation patterns and, thus, measures of $\mathrm{GP}$ and $\mathrm{CH}_{4}$ obtained in vitro.

\section{Endnote}

${ }^{1}$ Adjustment for different accuracies of measurements in different studies was carried out by weighting raw data by the inverse of the squared standard error divided by the mean of all the squared standard errors (St-Pierre, 2001) [20].

\section{Additional files}

Additional file 1: Appendix 1 List of the publications excluded from the database. (DOC $43 \mathrm{~kb}$ )

Additional file 2: Appendix 2 List of the publications included in the preliminary database. (DOC $40 \mathrm{~kb}$ )

\section{Acknowledgements}

This work was financed by the project "ARCHAEA — Feeding strategies to reduce methane emissions from dairy cows," Veneto Region Rural Development Programme (RDP) 2007-2013 "Progetto di Ateneo cod. CPDA 155250", University of Padova, Italy. Paper accepted as oral presentation at the XXI ASPA Congress, Milan, June 9-12, 2015.

\section{Authors' contributions}

All authors conceived of this meta-analysis, due to experience gained over the last years in the use of in vitro gas production technique for evaluating ruminant feeds. LM and MC gave substantial contributions to literature search, building of the database, and writing of the manuscript. FT, SS and LB contributed in editing and revising critically the manuscript. RM curated all aspects of the statistical analysis and gave final approval of the version to be published. All authors read and approved the final manuscript.

\section{Competing interests}

The authors declare that they have no competing interests.

\section{Author details}

${ }^{1}$ Department of Comparative Biomedicine and Food Science (BCA), University of Padova, Viale dell'Università 16, 35020 Legnaro (PD), Italy. ${ }^{2}$ Department of Agronomy, Food, Natural resources, Animals and Environment (DAFNAE), University of Padova, Viale dell'Università 16, 35020 Legnaro (PD), Italy.

Received: 11 November 2015 Accepted: 25 May 2016

Published online: 14 June 2016

\section{References}

1. Menke $\mathrm{KH}$, Steingass $\mathrm{H}$. Estimation of the energetic feed value obtained from chemical analysis and gas production using rumen fluid. Anim Res Dev. 1988;28:7-55

2. Pell AN, Schofield P. Computerized monitoring of gas production to measure forage digestion in vitro. J Dairy Sci. 1993;76(4):1063-73.

3. Theodorou MK, Williams BA, Dhanoa MS, McAllan AB, France J. A simple gas production method using a pressure transducer to determine the fermentation kinetics of ruminant feeds. Anim Feed Sci Technol. 1994;48(3-4):185-97.

4. Cone JW, Van Gelder AH, Visscher GJW, Oudshoorn L. Influence of rumen fluid and substrate concentration on fermentation kinetics measured with a fully automated time related gas production apparatus. Anim Feed Sci Technol. 1996:61(1-4):113-28.

5. Davies ZS, Mason D, Brooks AE, Griffith GW, Merry RJ, Theodorou MK. An automated system for measuring gas production from forages inoculated with rumen fluid and its use in determining the effect of enzymes on grass silage. Anim Feed Sci Technol. 2000;83(3-4):205-21.

6. Navarro-Villa A, O'Brien M, López S, Boland TM, O'Kiely P. Modifications of a gas production technique for assessing in vitro rumen methane production from feedstuffs. Anim Feed Sci Technol. 2011;166-167(6-7):163-74.

7. Pellikaan WF, Hendriks WH, Uwimana G, Bongers LJGM, Becker PM, Cone JW. A novel method to determine simultaneously methane production during in vitro gas production using fully automated equipment. Anim Feed Sci Technol. 2011;168(3-4):196-205.

8. Ramin M, Huhtanen P. Development of an in vitro method for determination of methane production kinetics using a fully automated in vitro gas system - a modelling approach. Anim Feed Sci Technol. 2012;174(3-4):190-200.

9. Getachew G, Blümmel M, Makkar HPS, Becker K. In vitro gas measuring techniques for assessment of nutritional quality of feeds: a review. Anim Feed Sci Technol. 1998;72(3-4):261-81.

10. Rymer C, Huntington JA, Williams BA, Givens DI. In vitro cumulative gas production techniques: history, methodological considerations and challenges. Anim Feed Sci Technol. 2005;123-124(1):9-30.

11. Cornou C, Storm IMLD, Hindrichsen IK, Worgan H, Bakewell E, Yáñez-Ruiz DR, Abecia L, Tagliapietra F, Cattani M, Ritz C, Hansen HH. A ring test of a wireless in vitro gas production system. Anim Prod Sci. 2013;53(6):585-92.

12. Patra AK, Yu Z. Effects of gas composition in headspace and bicarbonate concentrations in media on gas and methane production, degradability, and rumen fermentation using in vitro gas production techniques. J Dairy Sci. 2013;96(7):4592-600 
13. Gierus M, Schiborra A, Südekum KH, Rave G, Taube F. Comparison of gas accumulation profiles of several feeds using manual or automated gas production methods. Anim Feed Sci Technol. 2008;147(4):310-25.

14. Tagliapietra F, Cattani M, Bailoni L, Schiavon S. In vitro rumen fermentation: effect of headspace pressure on the gas production kinetics of corn meal and meadow hay. Anim Feed Sci Technol. 2010;158(3-4):197-201.

15. Cattani M, Tagliapietra F, Maccarana L, Hansen HH, Bailoni L, Schiavon S. Technical note: in vitro total gas and methane production measurements from closed or vented rumen batch culture systems. J Dairy Sci. 2014;97(3):1736-41.

16. Bodas R, Lopez S, Fernandez M, Garcia-Gonzalez R, Rodriguez AB, Wallace RJ, Gonzalez JS. In vitro screening of the potential of numerous plant species as antimethanogenic feed additives for ruminants. Anim Feed Sci Technol. 2008;145(1-4):245-58.

17. Van Soest PJ. Nutritional ecology of ruminants. 2nd ed. Ithaca: Cornell University Press; 1994.

18. Moe PW, Tyrrell HF. Methane production in dairy cows. J Dairy Sci. 1979; 62(10):1583-6.

19. Beuvink JMW, Spoelstra SF. Interactions between substrate, fermentation end-products, buffering systems and gas production upon fermentation of different carbohydrates by mixed rumen microorganisms in vitro. Appl Microbiol Biotechnol. 1992;37(4):505-9.

20. St-Pierre NR. Invited review: integrating quantitative findings from multiple studies using mixed model methodology. J Dairy Sci. 2001;84(4):741-55.

21. Institute SAS. SAS User's quide: basics. Cary: SAS Institute Inc.; 2007.

22. Oldick BS, Firkins JL, St-Pierre NR. Estimation of microbial nitrogen flow to the duodenum of cattle based on dry matter intake and diet composition. J Dairy Sci. 1999;82(7):1497-511.

23. Rawlings JO. Applied regression analysis. A research tool. 1st ed. Belmont: Wadsworth, Inc; 1988.

24. Belsley DA, Kuh E, Welsch RE. Regression diagnostics. New York: Wiley; 1980

25. Pirondini M, Malagutti L, Colombini S, Amodeo P, Crovetto GM. Methane yield from dry and lactating cows diets in the Po plain (Italy) using an in vitro gas production technique. Ital J Anim Sci. 2012;11(3):330-5.

26. Getachew G, Robinson PH, DePeters EJ, Taylor SJ, Gisi DD, Higginbotham GE, Riordan TJ. Methane production from commercial dairy rations estimated using an in vitro gas technique. Anim Feed Sci Technol. 2005;123-124(1):391-402.

27. Lovett DK, Bortolozzo A, Conaghan P, O'Kiely P, O'Mara FP. In vitro total and methane gas production as influenced by rate of nitrogen application, season of harvest and perennial ryegrass cultivar. Grass Forage Sci. 2004;59(3):227-32.

28. Martínez ME, Ranilla MJ, Tejido ML, Saro C, Carro MD. The effect of the diet fed to donor sheep on in vitro methane production and ruminal fermentation of diets of variable composition. Anim Feed Sci Technol. 2010;158(3-4):126-35.

29. Araujo RC, Pires AV, Mourau GB, Abdalla AL, Sallam SMA. Use of blanks to determine in vitro net gas and methane production when using rumen fermentation modifiers. Anim Feed Sci Technol. 2011;166-167(6-7):155-62.

30. Cone JW. The development, use and application of the gas production technique as the DLO institute for animal science and health (ID-DLO), lelystad, the Netherlands. In: Deaville ER, Owen E, Adesogen AT, Rymer C, Huntington JA, Lawrence TL, editors. Vitro techniques for measuring nutrient supply to ruminants. Edinburgh: BSAS; 1998. p. 65-78. BSAS Occ. Publ. No. 22.

31. Williams BA. Cumulative gas production techniques for forage evaluation. In: Givens DI, Owen E, Axford RFE, Omed HM, editors. Forage evaluation in ruminant nutrition. Wallingford: CABI Publishing; 2000. p. 189-213.

32. Menke K, Raab L, Salewski A, Steingass H, Fritz D, Schneider W. The estimation of the digestibility and metabolizable energy content of ruminant feedingstuffs from the gas production when they are incubated with rumen liquor in vitro. J Agric Sci (Camb). 1979;93:217-22.

33. Goncalves LMB, Borba AES. Study of gas production capacity by three sources of inocula. J Agric Sci (Camb). 1996;127:511-5.

34. Bueno ICS, Abdalla AL, Cabral Filho SLS, Vitta DMSS, Owen E, Mauricio RM Givens I, Sutton JD, Mould FL. Comparison of inocula from sheep and cattle for the in vitro gas production technique under tropical conditions. Proc Br Soc Anim Sci. 1999;151.

35. Cone JW, Van Gelder AH, Bachmann H. Influence of inoculum source on gas production profiles. Anim Feed Sci Technol. 2002;99(1-4):221-31.

36. Cone JW, Rodrigues MAM, Guedes CM, Blok MC. Comparison of protein fermentation characteristics in rumen fluid determined with the gas production technique and the nylon bag technique. Anim Feed Sci Technol. 2009:153(1-2):28-38.
37. Russell JB. Intracellular $\mathrm{pH}$ of acid-tolerant ruminal bacteria. Appl Environ Microbiol. 1991:57(11):3383-4.

38. Hungate RE. The rumen and its microbes. New York, NY, USA: Academic; 1966.

39. Ramin M, Krizsan SJ, Jančík F, Huhtanen P. Short communication: measurements of methane emissions from feed samples in filter bags or dispersed in the medium in an in vitro gas production system. J Dairy Sci. 2013;96(7):4643-6.

\section{Submit your next manuscript to BioMed Central and we will help you at every step:}

- We accept pre-submission inquiries

- Our selector tool helps you to find the most relevant journal

- We provide round the clock customer support

- Convenient online submission

- Thorough peer review

- Inclusion in PubMed and all major indexing services

- Maximum visibility for your research

Submit your manuscript at www.biomedcentral.com/submit
C BioMed Central 